\title{
Accidental perforation of the left ventricle with a Bonanno catheter
}

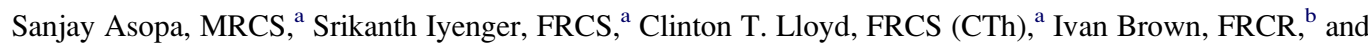 \\ Clifford W. Barlow, FRCS (CTh), PhD, ${ }^{\text {a }}$ Southampton, United Kingdom
}

This case report highlights the importance of surface anatomy and the potential complications of using a Bonanno. Catheter as a chest drain.

\section{CLINICAL SUMMARY}

An 82-year-old man presented with symptoms of increasing shortness of breath on exertion and nonproductive cough for more than a month. On examination, he had a respiratory rate of 20 breaths/min, dull percussion note, and decreased air entry in the left hemithorax. The rest of the examination was normal. The results of laboratory investigations were normal. Chest radiographic analysis demonstrated a large left-sided pleural effusion. A pleural tap was undertaken, and $20 \mathrm{~mL}$ of straw-colored pleural fluid was sent for histocytologic and microbiologic analysis.

A Bonanno 14-gauge catheter (Becton-Dickinson) was inserted in the left chest; there was pulsatile hemorrhage at the distal end of the catheter. Accidental perforation of an intrathoracic structure was suspected, and the catheter was immediately clamped. An emergency computed tomographic scan (Figure 1) of the chest was undertaken, which demonstrated the tip of the drain in the aortic root, passing through the left lung base into the left ventricle, with a reasonable amount of pericardial fluid and a large left pleural effusion. The patient was hemodynamically stable throughout and was transferred to our unit for further management.

In view of the radiologic evidence and the clinical picture with a risk of impending cardiac tamponade, the patient was transferred to the operating theater for emergency surgical removal of the catheter. After a standard median sternotomy incision, the pericardium was opened, and approximately $500 \mathrm{~mL}$ of blood was removed from around the heart; there was reasonable amount of tamponade at this point. The drain was found to enter the left ventricle on the lateral aspect of the heart in the circumflex artery territory. There was minimal leakage along the drain site. A single pledgeted suture was placed around the drain on the left ventricle, and the

\footnotetext{
From the Wessex Cardiothoracic Unit ${ }^{\mathrm{a}}$ and Wessex Cardiothoracic Radiology, Southampton General Hospital, Southampton, United Kingdom.

Received for publication Feb 24, 2008; revisions received March 19, 2008; accepted for publication March 21, 2008.

Address for reprints: Sanjay Asopa, MRCS, Wessex Cardiothoracic Unit, Southampton General Hospital, Tremona Rd, Southampton, SO16 6YD United Kingdom (E-mail: asopa2000@yahoo.com).

J Thorac Cardiovasc Surg 2009;137:1023-4

$0022-5223 / \$ 36.00$

Copyright (c) 2009 by The American Association for Thoracic Surgery doi:10.1016/j.jtcvs.2008.03.029
}

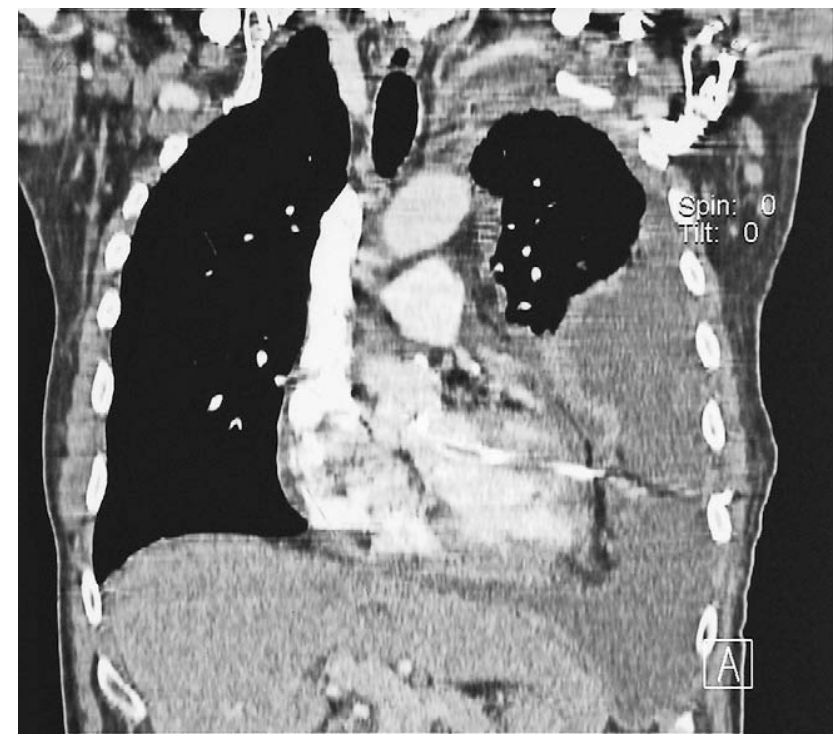

FIGURE 1. A computed tomographic image of the thorax. The path of the Bonanno catheter can be identified: it comes to lie in the left ventricular outflow tract. There is large left-sided pleural effusion.

drain was withdrawn with a good hemostatic result. The left pleura was opened and drained, and malignant deposits on the pleural surface were removed and sent for histopathologic analysis. The patient returned to the intensive care unit, where he made a steady recovery and was discharged home after a brief period of convalescence. Histology of the pleural tissue suggested low-grade lymphoma.

\section{DISCUSSION}

Tube thoracostomy and pigtail catheters are commonly used in the medical and surgical specialties to drain the pleural space of fluid, air, pus, and blood. Various techniques for insertion of intercostal drains to achieve a closed drainage system have been well documented in the British Thoracic Society guidelines. ${ }^{1}$ Incorrect insertion of a drain can have disastrous consequences. Case reports documenting the perforation of intrathoracic organs, including the left ventricle, ${ }^{2}$ as well as abdominal organs, are reported in the literature.

Insertion of a chest drain should be in the "triangle of safety." This is the triangle bordered by the anterior border of the latissimus dorsi, the lateral border of the pectoralis major muscle, a line superior to the horizontal level of the nipple, and an apex below the axilla. ${ }^{1}$ Knowledge of the anatomy of the anterior-lateral chest wall and its relation 
to the underlying intrathoracic and abdominal structures is important to avoid such complications. In our case the site of insertion of the drain was outside the "triangle of safety", (ie, lower than recommended). This is a common error most junior physicians make, as previously reported. ${ }^{3}$

Small catheters are well tolerated by patients and have been used effectively in draining simple pleural effusion, with acceptable complications. In situations of complex pleural effusions, hemothorax, empyema, and postthoracic procedures, their role is restricted. Tube thoracostomy by a cardiothoracic surgeon or ultrasound-guided drainage by a radiologist would be safer and achieve the effective result. ${ }^{4}$ In centers in which ultrasonography is available, insertion of a pigtail drain under ultrasonographic guidance is recommended, especially for complex effusions.

In our case the complication could have been prevented if there had been adherence to the British Thoracic Society guidelines for intercostal drain insertion. Also, the stylet and puncture needle of the Bonanno catheter is very long. Depth perception and needle control can be an issue while inserting them in the pleural cavity, for which they are not designed. We recommended changes to the design of such catheters to make them more user-friendly and reduce complications during insertion. ${ }^{5}$

To our knowledge, a drain piercing the left ventricle and lying in the left ventricular outflow tract with its tip in the aortic root has not been reported in the literature. Fortunately, early recognition of the misplaced drain and timely management led to the uneventful recovery of the patient. Strict adherence to the principles of drain insertion, ultrasound-guided insertion of pigtail catheters, or both can reduce the risks of complications.

\section{References}

1. Laws D, Neville E, Duffy J; Pleural Diseases Group, Standards of Care Committee, British Thoracic Society. BTS guidelines for the insertion of a chest drain. Thorax. 2003;58(suppl 2):53-9.

2. Abad C, Padron A. Accidental perforation of the left ventricle with a chest drain tube. Tex Heart Inst J. 2002;29:143.

3. Griffiths JR, Roberts N. Do junior doctors know where to insert chest drains safely? Postgrad Med J. 2005;81:456-8.

4. Cantin L, Chartrand-Lefebvre C, Lepanto L, Gianfelice D, Rabbat A, Aubin B, et al. Chest tube drainage under radiological guidance for pleural effusion and pneumothorax in a tertiary care university teaching hospital: review of 51 cases. Can Respir J. 2005;12:29-33.

5. Asopa S, Patel A. Bonnano's catheter: a less invasive and cost-effective alternative for drainage of pleural effusion. J Thorac Cardiovasc Surg. 2006;132:1503-4.

\section{Give the patient another chance: Peratrial device closure of a secundum atrial septal defect that failed percutaneous device closure}

Kai-yu Tao, MS, ${ }^{\text {a }}$ Qi An, MS, ${ }^{a}$ Chang-ping Gan, MS, ${ }^{a}$ Hong Tang, MD,${ }^{b}$ Yuan Feng, MD, ${ }^{\mathrm{c}}$ and Hai-bo Song, MD,${ }^{\mathrm{d}}$ Chengdu, China

Percutaneous device closure of a secundum atrial septal defect (ASD) is an effective and fairly safe alternative to surgical intervention, but it is technically challenging and is not always performed smoothly in patients with large ASDs. ${ }^{1,2}$ We report a deft recovery of a dislocated ASD occluder in the right atrium without cardiopulmonary bypass (CPB) through an incision on the right atrial wall with inferior

\footnotetext{
From the Departments of Thoracic and Cardiovascular Surgery, ${ }^{\mathrm{a}}$ Echocardiography, Cardiology, ${ }^{\mathrm{c}}$ and Anesthesiology, ${ }^{\mathrm{d}}$ West China Hospital, Sichuan University, Chengdu, China.

Received for publication Jan 11, 2008; revisions received Feb 15, 2008; accepted for publication March 23, 2008.

Address for reprints: Qi An, MS, Department of Thoracic and Cardiovascular Surgery, West China Hospital, Sichuan University, Chengdu, Sichuan 610041, China (E-mail: anqi8890@163.com).

J Thorac Cardiovasc Surg 2009; 137:1024-7

$0022-5223 / \$ 36.00$

Copyright (c) 2009 by The American Association for Thoracic Surgery doi:10.1016/j.jtcvs.2008.03.030
}

partial median sternotomy, after which a peratrial device closure of the ASD was successfully performed.

\section{CLINICAL SUMMARY}

A 33-year-old woman with a large secundum ASD of 32 $\times 28 \times 27 \mathrm{~mm}$ in size with a $13-\mathrm{mm}$ superior rim, a $12-\mathrm{mm}$ inferior rim, and an insufficient anterior rim was referred to our hospital. A percutaneous device closure was performed under fluoroscopic guidance in a catheterization laboratory, but the 34-mm occluder was dislocated into the right atrium after its release from the cable, and attempts to recover the occluder were failed. Considering the risk of blocking the tricuspid (Figure 1, A), an emergency operation was required. In the operating room the right atrium was exposed with an inferior partial median sternotomy. Meanwhile, one finger of the glove was cut down to make a finger cot, which was put on the surgeon's index finger outside the glove, and then concealed a small hook between the finger 